\title{
Considerações sobre as origens das dificuldades com os conteúdos de Física, a partir de depoimentos de alunos de uma escola pública de Fortaleza
}

\begin{abstract}
Resumo: Reconhecendo a existência de percepções negativas dos físicos, como profissionais, e da Física, enquanto componente curricular da educação básica, este trabalho busca identificar indícios das origens dessas aversões, como podem ter se instalado e evoluído e se podem ter interferido nas aprendizagens dos estudantes. Para tanto, realizou-se um estudo de caso em uma escola de ensino médio da rede pública estadual do Ceará. Os dados aqui apresentados referem-se às entrevistas, semiestruturadas, realizadas com 12 estudantes das três séries. A análise das informações, feita através de leitura impregnativa, sugere que há associações, quase exclusivas, da disciplina Ciências, do ensino fundamental, com Biologia; que há correlações entre as dificuldades em Matemática e Física; que há professores que conseguem envolver seus alunos, o que permite concluir que as experiências positivas, quando existem, decorrem de ações isoladas dos professores; que os alunos não sabem e não gostam de Matemática, fato que interfere nas aprendizagens de Física e, ainda, que as aversões aos conteúdos de Física não parecem nascer no Ensino Fundamental.

Palavras-chave: Processo de ensino-aprendizagem. Ensino médio. Ensino de física.
\end{abstract}

\section{Introdução}

Os dados das avaliações institucionais realizadas com alunos das escolas brasileiras, como Sistema Permanente de Avaliação da Educação Básica (SPAECE), ${ }^{1}$ Sistema de Avaliação da Educação Básica (SAEB), Prova Brasil ou PISA têm, continuamente, apresentado resultados bastante preocupantes que, no geral, confirmam

aquilo que os professores da educação básica podem perceber no dia-a-dia dos seus trabalhos e que, vez por outra, explicitam-se em matérias jornalísticas: ainda que seja maior o acesso de adolescentes e jovens brasileiros às escolas de ensino fundamental e médio, ele não tem sido acompanhado por reais apropriações de conhecimentos considerados básicos, o que evidencia que não estamos conseguindo efetivar o direito à educação, como prescrito na Constituição Federal de 1988 e na Lei de Diretrizes e Bases da Educação Nacional, de 1996.

Reprovações ou aprovações sem domínio de conhecimentos mínimos são facetas dos processos de exclusão social que, às vezes, evidenciam e, às vezes, mascaram alguns dos enormes problemas
Idevaldo da Silva Bodião Universidade Federal do Ceará idbodiao@uol.com.br

Carin Rochane Costa de Araújo Secretaria de Educação do Estado do Ceará

carincosta@hotmail.com
(1) Criado em 1992, o SPAECE é uma iniciativa da Secretaria de Educação Básica do Estado do Ceará e tem como objetivo fornecer subsídios para o monitoramento e as formulações das políticas para o setor. 
(2) Dados obtidos em: <http:// www.vestibular.ufri.br/2008/ estatisticas online/MediaDiscand. asp >. Acesso em: 16 jun. 2008.

(3) Dados obtidos em <http:// educacao.uol.com.br/ infograficos/2011/09/12/consulte-anota-da-sua-escola-no-enem-2010. htm>. Acesso em: 26 jan.2012. a serem enfrentados, de modo adequado, pelas nossas escolas. É perceptível, também, que as dificuldades de aprendizagens e as reprovações não estão distribuídas aleatoriamente, concentrando-se em duas ou três disciplinas, que são facilmente identificáveis. Para os professores que estão nas salas de aula de escolas do ensino médio, por exemplo, não é difícil apontar Física, Química e Matemática como aquelas em que seus alunos apresentam os piores desempenhos.

Nos resultados dos vestibulares, que podem ser tomados como um dos indicadores dessas percepções, a disciplina Física parece se destacar dentre aquelas em que os alunos têm as performances mais frágeis. Dados do processo seletivo da Universidade Federal do Rio de Janeiro (UFRJ), de 2008, por exemplo, confirmam essa tendência: a prova de Física apresenta a pior média $(2,297)^{2}$ acompanhada, nessa ordem, por História, Química e Matemática; a surpresa é termos a prova de História incluída nesse grupo. Durante a década de 1990, na cidade de Fortaleza, era corrente a preocupação de muitos vestibulandos em "não zerar" em Física.

A comparação dos resultados no Exame Nacional do Ensino Médio (ENEM) $2010^{3}$ da escola com maior média no Brasil, daquela com maior média no Ceará, que é particular, e da escola pública com melhor média no estado evidencia que as pontuações de Ciências da Natureza, junto com as de Linguagens e Códigos, nos três casos, são as piores das cinco avaliações realizadas, estando, como é evidente, sempre abaixo das médias das referidas escolas. Sem entrar no mérito específico da referida avaliação, esses dados ajudam a consolidar a dimensão do que aqui está a se dizer: parte substantiva dos estudantes brasileiros termina o ensino médio sem se apropriar de conhecimentos básicos de Física, Química e Biologia, por exemplo.

Szajanberg e Zakon (2001, p. 1) apresentam argumentação semelhante, referindo-se aos conteúdos de Física, "de qualquer curso (do ensino superior) onde tal matéria seja obrigatória" e assinalam um problema que consideram mais grave: o medo que os alunos têm dessa disciplina, sintoma que denominam "síndrome do patinho feio". D'Agostin e outros colaboradores (2006) defendem o mesmo ponto de vista, cogitando que esse medo/aversão aos conteúdos de Física, em alunos do ensino médio, pode se constituir em importante fator a dificultar melhores desempenhos nessa disciplina. Caniato (1987, p. 46), tecendo críticas à forma com que 
são conduzidas as aulas de Ciências da Natureza, toca no mesmo tema, e afirma: "Essa aversão se manifesta especialmente em relação às disciplinas como Física e Química que transformam-se em verdadeiro 'terror' e, para a maioria, de dificuldade insuperável." Fiolhais e Trindade (2003) e Rosa e Rosa (2004), ainda que se refiram a universos distintos, tecem comentários semelhantes.

Objetivando, também, encontrar elementos que pudessem ajudar a explicar essa aversão, D'Agostin e outros colaboradores (2006) propuseram-se, entre outras questões, perscrutar as concepções dos alunos a respeito dos trabalhos dos cientistas. Naquilo que é possível comparar, esse estudo recente mostra razoável concordância com trabalhos realizados há cerca de 40 anos, com grupos de alunos distintos e de nacionalidades diferentes, o que evidencia um forte enraizamento simbólico dessas concepções.

Enquanto Mead e Métraux (1957) se ocuparam de alunos de 120 escolas americanas, equivalentes ao nosso ensino médio, Beardslee e O'Dowd (1961) trabalharam com graduandos de quatro importantes escolas de ensino superior do Nordeste dos EUA e Gómezgil (1975) focou sua pesquisa em estudantes da região metropolitana da Cidade do México, que cursavam escolas secundárias e preparatórias para o ingresso no ensino superior. Esses estudos mostram, com graus distintos de evidências, que os estudantes apresentam visões positivas e atrativas das Ciências, embora, ao mesmo tempo, apresentem restrições e pouquíssima afinidade pessoal com as carreiras profissionais dos "cientistas", já que, embora estes sejam considerados muito inteligentes, são vistos como seres insociáveis, egoístas e dedicados quase exclusivamente às suas pesquisas.

Chambers (1983), trabalhando com crianças dos cinco aos 11 anos de idade, de duas cidades canadenses, cinco americanas e uma australiana, busca descobrir quando as características que tipificam os cientistas começam a aparecer no universo infantil, reconhecidas na figura estereotipada do profissional de óculos e barbas que, de avental branco, trabalha sozinho, envolvido por equipamentos, vidrarias e substâncias estranhas. Interessa destacar dois aspectos que emergem desses estudos: enquanto Chambers (1983) chega a afirmar que é no segundo ano, quando as crianças têm perto de oito anos de idade, que o estereótipo de cientista começa a se construir no imaginário infantil, Beardslee e O'Dowd (1961) afirmam que, quando se abordam as especificidades dessas percepções, os biólogos são vistos como aqueles cujo perfil está mais próximo do 
ideal norte americano, enquanto aos físicos é atribuída a maioria dos adjetivos negativos dados aos cientistas.

Pode-se dizer que, pelo menos para esses autores, as crianças cheguem às séries terminais do ensino fundamental com visões bastante elaboradas, ainda que estereotipadas, da Ciência, dos cientistas e de seus trabalhos e que essas percepções não são exatamente favoráveis aos físicos.

Tal percepção é parcialmente corroborada, por exemplo, por Maurina e Pinheiro (2005) que consideram que a visão não positiva da Física, enquanto componente curricular, e dos físicos, como categoria profissional, é construída mesmo antes de os alunos terem iniciado os estudos nessa disciplina, chegando a afirmar que esses elementos podem se constituir em obstáculos dessas aprendizagens, durante a escolarização de ensino médio.

Assim, reconhecendo que há registros de péssimas performances escolares no ensino médio em disciplinas como Física, Química, e Matemática, reconhecendo, também, que as visões dos estudantes sobre os cientistas e as Ciências podem começar a se constituir antes desse período de escolarização e, principalmente, que essas percepções podem influenciar as trajetórias escolares desses estudantes, nessas disciplinas específicas, considerou-se importante empreender esta pesquisa.

\section{A pesquisa}

O estudo a que se vincula este trabalho busca identificar, no processo de escolarização, indícios das origens de eventuais aversões à Física como disciplina curricular, como elas podem ter se instalado e evoluído e como podem interferir/ter interferido nas aprendizagens de estudantes de uma escola pública estadual.

Em função da sua natureza, optou-se por realizar uma pesquisa com abordagem qualitativa e, considerando-se o recorte específico deste trabalho, fez-se a opção por realizá-lo como um estudo de caso, por entender, como Bogdan e Biklen (1994), que visa compreender aspectos do comportamento de sujeitos, entendidos como entidades singulares, no ambiente natural de suas vivências.

Como é próprio dos estudos de casos, utilizamos diferentes fontes e instrumentos de informação, tais como observações, entrevistas e documentos, procurando representar os distintos e, às vezes, conflitantes pontos de vista presentes numa determinada 
situação-instituição. (LÜDKE; ANDRÉ, 1986) Ainda que se tenha consultado documentos e feito visitas à escola, os dados deste traba1ho advêm, de forma privilegiada, de entrevistas semiestruturadas; elas foram utilizadas por entendermos que possibilitam que os diálogos, como conversas, possam fluir mais natural e livremente, permitindo, assim, melhor abordar assuntos mais pessoais e temas mais complexos, como aqueles aqui tratados. (BOGDAN; BIKLEN, 1994; LÜDKE; ANDRÉ, 1986)

A pesquisa foi realizada em um estabelecimento de ensino médio da rede pública estadual, localizada na região central de Fortaleza, que atende alunos vindos de diversas regiões da cidade, o que inclui aqueles que moram em locais bem distantes. É reconhecida como uma boa escola, o que ajuda a explicar essa afluência de alunos.

No período de visitas à escola, pôde-se observá-la em condições de funcionamento, o que permite afirmar que ela conta com uma estrutura relativamente boa, pois tem uma biblioteca com acervo substantivo, tem laboratório de Física, objeto de interesse deste estudo, onde os alunos podem ter aulas experimentais regulares, possui laboratório de informática, além de salas de aula que apresentam boas condições de funcionamento, pois são amplas, bastante ventiladas e bem iluminadas, ainda que em algumas delas se tenha um número grande de alunos.

As entrevistas, feitas com base em um roteiro previamente construído, visavam investigar as percepções dos alunos sobre o ensino da disciplina Física, de modo a perceber como a encaravam, quais as dificuldades que encontravam para aprendê-la e a forma como viam as atuações dos seus professores. Intencionando descobrir se durante a escolarização de ensino fundamental poder-se-ia identificar algumas das raízes de possíveis aversões dos alunos aos conteúdos de Física, o foco inicial das entrevistas voltou-se para os conteúdos das aulas de Ciências.

Foram entrevistados 12 alunos, sendo quatro de cada uma das séries do ensino médio; procedeu-se dessa forma para tentar acompanhar indícios de evolução das percepções dos estudantes, durante esse nível de escolarização. Eles foram escolhidos por sorteio e todas as entrevistas foram realizadas na própria escola, como forma de preservar a familiarização dos entrevistados com o ambiente de sua realização. 
Os entrevistados, quatro garotos e oito meninas, estudavam no período diurno e tinham idades variando entre 14 e 18 anos, fazendo parte de núcleos familiares com composições bem distintas. Alguns tinham irmãos cursando o ensino fundamental ou o ensino médio ou, ainda, fazendo cursos superiores, havendo, também, casos de irmãos que o haviam completado. De comum, entre eles, o fato de nenhum morar no mesmo bairro onde está localizada a escola.

Para a organização e análise dos dados obtidos a partir das entrevistas, procedeu-se a leituras impregnativas, procedimento que permite, através de processos de interpretações sucessivas e gradativamente mais elaboradas, o estabelecimento de relações entre informações que se constituem nos elementos importantes na definição das categorias de organização (MICHELAT, 1982), ou categorias descritivas. (ANDRÉ, 2005)

Essas definições se estabelecem "por aproximações sucessivas", em construções cada vez mais completas e consistentes; o conjunto de dados aqui apresentado pretende, apenas, refletir uma possível leitura do real, como ele parece ter sido percebido pelos entrevistados. Por outro lado, cientes de que, pela sua natureza, a pesquisa tenha se voltado para uma singular realidade, geograficamente localizada e historicamente datada, não se pretende que este estudo venha a ser entendido como uma representação generalizável para as escolas de Fortaleza, o que, no entanto, não nos impede de cogitar que talvez estejamos fazendo "[...] afirmações universais sobre processos sociais gerais" (BOGDAN; BIKLEN, 1994, p. 66) que ali estiveram a se desenvolver.

\section{O que dizem os alunos de suas experiências escolares}

$$
\begin{array}{r}
\text { "Ciências parece biologia": as relações com as ciências } \\
\text { naturais, no ensino fundamental }
\end{array}
$$

Ainda que se reconheça não existir, desde o início da escolarização de ensino fundamental, uma disciplina nomeada "Física", sabe-se que há conteúdos oriundos desse arcabouço científico distribuídos ao longo desse nível da educação básica. Considerando-se essa continuidade, pretendeu-se perscrutar as relações que os alunos estabeleceram com esses conteúdos e como elas podem ter ajudado, ou não, a estabelecer vínculos afáveis com a disciplina Física, como ela é apresentada no ensino médio. 
Curiosamente, os alunos entrevistados não identificaram, nos conteúdos estudados em Ciências, nenhum pertencimento à Física, seja pela falta dessa lembrança, seja pela identificação pessoal com outros conteúdos; DSS, ${ }^{4}$ do $1^{\circ}$ ano, diz: "não lembro bem da matéria de Ciências de cada série." Noutro momento da entrevista, ele mesmo identifica conteúdos de Química, reconhece-os como sendo conduzidos pela mesma professora de Ciências, mas não faz qualquer correlação entre as disciplinas, ao afirmar: "Entendia melhor a aula de Química, embora fosse a mesma professora de Ciências." (DSS, $1^{\circ}$ ano)

JDS, também do $1^{\circ}$ ano, lembrou, apenas, de alguns conteúdos que vinculamos, mais diretamente, à Biologia, ao dizer: "Em Ciências, só lembro que era mais corpo humano."

Quando discorria sobre suas experiências como aluno do ensino médio, KNI ( $1^{\circ}$ ano) comentou: "[...] Química não é Ciências, porque Ciências parece Biologia." Raciocínio, aliás, que não pode ser considerado de todo errado, pois se formos observar os livros geralmente utilizados no ensino fundamental, facilmente perceberemos que a maioria dos conteúdos que são tratados na disciplina Ciências realmente se referem a conceitos de Biologia, sobrando pouco espaço para Química e Física, que só aparecem, como tal, no último ano do ensino fundamental, como o identifica JDS $\left(1^{\circ}\right.$ ano): "No $9^{\circ}$ ano, Ciências no $1^{\circ}$ semestre era Química e no $2^{\circ}$ era Física, mas quase não teve aula de Física."

Nas intervenções dos alunos há predominância de identificações dos conteúdos de Ciências com os de Biologia, como, por exemplo:

Não lembro de nada de Física, lembro tudo que a professora falou de Química e Biologia. (DSS, $1^{\circ}$ ano)

[… porque Biologia é a mesma coisa de Ciências. (ACL, $2^{\circ}$ ano)

[...] não tinha mais Ciências, era só Química, e Química não é Ciências... (KNI, $1^{\circ}$ ano)

Além de aparecer bem pouco na integralização curricular, ainda há casos, como o relatado por JDS, em que as aulas efetivas ocorrem em número menor ainda "[...] quase não teve aula de Física [...]", o que pode ajudar a entender a afirmação de DSS, ao dizer "não lembro de nada de Física."

$\operatorname{KMF}\left(2^{\circ}\right.$ ano) foi preciso, ao explicitar a subdivisão, no atual $9^{\circ}$ ano, da disciplina Ciências, nas áreas específicas: "já não teve
(4) Optou-se por nomear os alunos entrevistados por uma combinação de letras, como uma forma de preservar suas identidades. 
(5) O "ensino fundamental II", também identificado como "anos terminais do ensino fundamental" engloba as classes de $6^{\circ}$ ao $9^{\circ}$ ano. mais Ciências, já foi Física, Química e Biologia, não teve Ciências, foi dividido." Por outro lado, a argumentação de KNI ( $1^{\circ}$ ano) de que "a Biologia do Ensino Médio é o que existe de mais parecido com a matéria de Ciências do Ensino Fundamental II"5 pode ser entendida como um indício da percepção da continuidade de conteúdos, ainda que identificados por meio de disciplinas diferentes, nesses dois níveis de escolarização.

O conjunto das intervenções dos alunos parece construir uma organização curricular, para as séries terminais do ensino fundamental, onde, ao lado das demais, aparece uma disciplina com o nome de "Ciências", que aborda quase exclusivamente conteúdos de Biologia, ou reconhecidos como tal, e, no último ano desse nível de escolarização aparecem as disciplinas Química e Física. Assim, as entrevistas parecem indicar que, para esses alunos, Ciências, do ensino fundamental, se parece com Biologia.

"Como não gosto de matemática, também não gosto de física”: as influências da matemática no ensino de física

Em várias avaliações institucionais a que têm sido submetidos os estudantes brasileiros, há evidências explícitas das enormes dificuldades nas operações com os conteúdos, às vezes, elementares de Matemática; nos seus depoimentos, os alunos entrevistados não apenas as reconhecem, como também, identificam seus espraiamentos para outras disciplinas como, por exemplo, Física.

Em alguns casos, os alunos entrevistados apontam as dificuldades específicas com aquela disciplina, como o fez KNI, do $1^{\circ}$ ano "[...] no final do ano ele falou um pouco de Física, mas só dava aula de Matemática e eu .não entendia nada", ou LGF, do $3^{\circ}$ ano, "Minha matéria predileta era História, pois o professor era bom e o livro também. A Matemática era a matéria que eu menos gostava." Em casos mais extremos, esses estranhamentos se transformam em aversões, evidentes em depoimentos como o de MAAA (2 ano): "[...] odeio Matemática, minha matéria preferida é História."

Vários foram os alunos que, com clareza, associaram suas aversões à Física à forma matematizada como, geralmente, é abordada, durante as aulas do ensino médio nas escolas brasileiras. KMF $\left(2^{\circ}\right.$ ano) afirma: "Nunca gostei de Física, tem muita Matemática." DSS ( $1^{\circ}$ ano) parece fazer-lhe coro, ao dizer: "Física é muita fórmula, é muito difícil." Nenhum deles conseguiu ser tão preciso quanto 
HARJ ( $3^{\circ}$ ano), ao formular uma síntese exemplar, que estabelece vinculações claras, entre suas aversões à Matemática e à Física, dizendo: "Não gosto de Física, porque tem cálculo e como não gosto de Matemática, também não gosto de Física."

Analisando-se as demais respostas, é possível perceber que oito alunos, dentre os 12 entrevistados, explicitaram não gostar ou, pelo menos, ter dificuldades com os conteúdos de Matemática.

Pode-se conjecturar que a possível aversão dos alunos aos conteúdos de Física, decorre, também, das dificuldades que eles têm com os conteúdos de Matemática; nesse caso, elas decorreriam, pelo menos em parte, das atuações dos próprios professores que, muitas vezes, priorizam um enfoque quase exclusivamente matematizado, transformando o aprendizado de Física na apropriação de um conjunto de fórmulas e no adestramento em um conjunto de rotinas de cálculos, entendidas como essenciais para as resoluções dos exercícios propostos. Procedendo dessa maneira, transportam para a Física as mesmas dificuldades de compreensão e as mesmas resistências que seus alunos sentem pela Matemática, levando-os a vê-la, igualmente, como difícil e desinteressante.

\section{"Gostava de física, porque o professor era ótimo": professores diferentes e metodologias diferenciadas}

Em momentos distintos das suas entrevistas, os alunos fizeram alusões aos trabalhos de seus professores, identificando, de forma positiva, situações em que estes os envolveram, criando momentos de encantamentos com as disciplinas curriculares.

DSS ( $1^{\circ}$ ano) lembra-se de ter gostado de Química, na $8^{\text {a }}$ série, pois "o professor era legal"; disse, também, não se lembrar de Física, no ensino fundamental, mas sim de Biologia e Química, e que entendia melhor os conteúdos desta última. Mais à frente, ele dá a entender que a forma, não usual, de serem conduzidas as aulas teve influência no fato de gostar de Química.

JDS ( $1^{\circ}$ ano) lembra, com entusiasmo, que quando o professor de Matemática e Ciências tirou licença, o substituto conduziu aulas "montando", junto com os seus alunos, a tabela periódica; refere-se, também, ao fato, que ele considerava positivo, de terem realizado encenações de pequenas peças teatrais, além de terem participado de debates promovidos durante as aulas. 
Nas alusões às aulas identificadas como interessantes, vários depoimentos referem-se àquelas vinculadas a atividades experimentais, como no caso de KNI ( $1^{\circ}$ ano), ao dizer: "[... ] a melhor aula foi a que o professor fez experiências distinguindo o que tinha a ver com Física e o que tinha a ver com Química."

JDS ( $1^{\circ}$ ano) também se manifestou claramente a favor de aulas experimentais, mesmo sem citar qualquer conteúdo específico "Se toda aula fosse prática seria mais simples", enquanto AKAS, do $3^{\circ}$ ano, reafirma essa percepção, aplicando-a a um estudo de Hidrostática, afirmando: "[...] o professor usou um aparelho lá e explicou, bem direitinho, aí eu entendi o Empuxo."

Recurso pedagógico de substantivo vigor e que, de certa forma, poderia ser considerado como natural nas aulas das disciplinas da área de Ciências da Natureza, as atividades experimentais, realizadas, ou não, em laboratórios, têm sido, no geral, pouco usadas, mesmo em escolas que possuem laboratórios.

Em alguns casos, o papel, importante, que as atuações dos professores têm, no processo de identificação e envolvimento dos alunos com as disciplinas escolares, é explícito, como na resposta dada por AKAS ( $3^{\circ}$ ano) que diz gostar "muito da matéria, pelo professor e pela aula que ele dá" para, mais à frente, reiterar: "No $1^{\circ}$ ano gostava de Física porque o professor era ótimo e ensinou super bem, aí passei a tirar boas notas [...] no $2^{\circ}$ ano, deixei de gostar de Matemática porque o professor não ensinava bem."

LGF, colega do $3^{\circ}$ ano, mantém o mesmo diapasão, ao afirmar: "No $2^{\circ}$ ano gostava de Física, era a melhor aula, por causa do professor $[\ldots]$ no $3^{\circ}$ deixei de gostar de Física porque o novo professor não tem paciência para explicar e passei a gostar de Matemática e Português."

Dessa forma, pode-se cogitar que, mesmo com dificuldades em descrever as características das metodologias utilizadas por seus professores, os alunos percebem diferenças nas suas atuações e, em alguns casos, veem aumentar os seus interesses por essas aulas, por vezes, com melhoras nos resultados dos seus aproveitamentos escolares. Tais constatações reforçam a ideia de que os professores têm um acentuado papel, ainda que não exclusivo, tanto no surgimento, quanto na superação das dificuldades encontradas pelos seus alunos, quaisquer que sejam as disciplinas curriculares e que abordagens diversificadas podem se constituir em elementos 
importantes nos processos de identificação dos alunos com os conteúdos disciplinares.

\section{Considerações finais}

Há experiências posistivas, ainda que isoladas

A identificação de várias situações onde os professores, em função de abordagens diversificadas e criativas, foram capazes de "seduzir" alguns dos alunos, permitindo-lhes aproximações mais prazerosas com os conteúdos curriculares, nos permite cogitar que esses encantamentos facilitaram as aproximações dos alunos com esses conteúdos, com influências positivas para os seus estudos. Tal percepção tem o mesmo teor daquela identificada por Moura e Vale (2001, p. 141), em estudo feito com alunos de Ciências de $5^{\text {as }} \mathrm{e}$ $6^{\text {as }}$ séries do ensino fundamental, quando afirmam: "[...] se acham o professor legal, então gostam das aulas; quando não gostam do professor, também não gostam de Ciências."

Ocuparam lugar privilegiado nas interlocuções com os alunos envolvidos neste estudo as práticas de aulas experimentais, ainda que, por vezes, tenham se reduzido a realizações de experimentos simples (e demonstrativos) executados nas próprias salas de aula. Apontados como relevantes para o ensino de Física, os enfoques experimentais poderiam se constituir em uma das formas extremamente positivas de condução desses conteúdos, apresentando-se como uma oposição natural à excessiva matematização desses conceitos. Não que se queira atribuir, exclusivamente, ao uso de aulas experimentais uma potência que elas não têm, trata-se, no entanto, de reconhecer-lhes virtudes que pouco têm sido exploradas no cotidiano das escolas brasileiras. (MOURA; VALE, 2001)

Em pesquisa em que abordam os problemas e perspectivas do ensino de Física em uma cidade paulista, Silva e Saad (2001) registram que, a despeito das aulas experimentais terem suas importâncias enfatizadas pelos 23 professores estudados, apenas três as utilizavam com regularidade; as justificativas apontadas para tais ausências foram:

duração da aula, muitas vezes incompatível com o tempo exigido para realização do experimento, o número elevado de alunos em cada sala dificultando a utilização da sala ambiente, a falta de

R. FACED, Salvador, n. 20, p. 65-81, jul./dez. 2011 
material e condições de uso do laboratório, despreparo docente para implementá-las, dificuldades apostas pela administração da escola e orientação da escola para a preparação para os vestibulares, no caso de escolas particulares. (SILVA; SAAD, 2001, p. 53)

Deixando de lado a problemática específica das escolas particulares, convém lembrar que nas escolas públicas, os conteúdos de Física são, em geral, tratados com duas aulas semanais, o que não se mostra suficiente para a apresentação dos conteúdos curriculares mínimos, problema que se agrava com a inclusão de abordagens experimentais que, quase sempre, são mais demoradas que aquelas expositivas. Ao mesmo tempo, é importante lembrar que não é incomum encontrarmos professores sem formação inicial em licenciaturas específicas nas áreas de Física e Química, por exemplo, fato que ajuda a entender a falta de atividades experimentais nas escolas de educação básica (GEYMONAT, 1997); muitos desses profissionais são graduados em engenharia ou em outras áreas técnicas, cujas formações não podem ser consideradas suficientes para lhes criar hábitos e sedimentar segurança nas conduções de aulas de laboratórios. Se essa fragilidade é evidente em professores de Física que estão em pleno exercício nas escolas da rede estadual paulista, como no estudo apontado anteriormente, convém não esquecer que tais precariedades são mais acentuadas nos estabelecimentos de ensino da região Nordeste.

As secretarias de educação parecem ter dificuldades em encontrar, em número suficiente, licenciados em áreas como a do ensino de Física, por exemplo, o que as leva a lançar mão de profissionais formados em áreas afins, com as decorrências que isso acarreta. Parece essencial que essa precariedade venha a ser corrigida com consistentes programas de formação em serviço que, nesse caso, precisam se diferenciar das atuais propostas de titulação, sejam as complementações pedagógicas de estudos, sejam os cursos de pós-graduação lato-sensu. Há uma vasta bibliografia que advoga a recuperação da figura do professor como um "profissional reflexivo" e da instituição de grupos de formação, nos próprios espaços de trabalho, dos quais Nóvoa (1997), Pimenta e Ghedin (2002) e Parrilla e Daniels (2004) são alguns exemplos; há, também, interessantes experiências de formação continuada, com professores de Física, como a relatada por Scarinci (2010), por exemplo. Todas parecem continuar sendo olimpicamente desconsideradas 
pelos gestores educacionais brasileiros, afeitos a alcances generosos e prazos exíguos.

Ao mesmo tempo, é bom lembrar que a efetiva implantação da lei do piso salarial profissional nacional para os profissionais do magistério público da educação básica, ${ }^{6}$ sobretudo no que diz respeito à dedicação de um terço da lotação em atividades fora das salas de aula, associada a convidativos planos de cargos, carreiras e remunerações, pode se constituir em importante fator de atração de promissores estudantes para o exercício das atividades docentes.

Os alunos não sabem e não gostam de matemática

Naquilo que é possível, a partir das entrevistas realizadas, localizar como focos das dificuldades e, por que não dizer, das aversões aos conteúdos de Física, pode-se afirmar que um deles aponta para a forma exageradamente matematizada como eles são tratados.

Parece legítimo afirmar que a recorrente abordagem desses conteúdos assentados em procedimentos metodológicos filiados à lógica da pedagogia tradicional (LIBÂNEO, 1993; MIZUKAMI, 1986), com os conteúdos determinados pelos livros didáticos, que acabam "por se constituir num conjunto de leis e definições, muitas vezes representadas através de fórmulas, em exercícios repetitivos de aplicação numérica" (SILVA; SAAD, 2001, p. 53), tanto não se mostram adequados a fazê-los compreender esses assuntos, como também, ajudam a construir barreiras de rejeições entre os alunos e essa disciplina curricular. Os frágeis domínios de conhecimentos elementares de Matemática, como operações com frações, resoluções de equações de $1^{\circ}$ e $2^{\circ}$ graus e noções de geometria e trigonometria, por exemplo, atributos exigidos para as soluções de muitos dos exercícios de Física, como ela é abordada nas escolas de ensino médio, podem ser arrolados como exemplos dessas dificuldades, presentes no dia a dia escolar.

A despeito de existirem algumas propostas metodologicamente diferenciadas, como, por exemplo, o são a do PROJETO DE ENSINO DE FÍSICA(PEF)/1984 e a do GRUPO DE REELABORAÇÃO DO ENSINO DE FÍSICA (GREF/1990) e de expressivo conjunto de experiências localizadas, a escola brasileira parece confirmar, ano a ano, sua predileção pelo modus operandi dos cursinhos pré-vestibulares, utilizando, e cada vez mais, as versões editoriais daquilo que, em passado recente, foram as suas apostilas, das quais 
Ramalho Junior, Ferraro e Soares (2007) é, em Física, o exemplo mais emblemático.

Parece necessário entender por que traços interessantes de algumas daquelas experiências, bastante mais elaboradas do que as práticas curriculares atuais, não se disseminaram pelas nossas escolas de ensino médio. Na esteira dessa lógica, é preciso buscar as responsabilidades das secretarias de educação, em princípio, as articuladoras institucionais das práticas e inovações pedagógicas sem, no entanto, deixar de olhar, também, para o papel que (não) têm exercido os agentes responsáveis tanto pelas pesquisas na área do ensino de Física, quanto pela sua formação inicial, as instituições de ensino superior. (BODIÃO, 2007)

\section{As aversões à física não parecem nascer no ensino fundamental}

Embora, aparentemente, simples, há, nas elaborações deste trabalho, elementos que nos permitem dizer que as aversões aos conteúdos de Física não parecem nascer durante a escolarização de ensino fundamental.

Para os estudantes aqui entrevistados, as possíveis vinculações entre a Física, os físicos e as aprendizagens de Ciências, não encontram esteio para florescer, pois, nas suas percepções, esta disciplina, própria do ensino fundamental, parece se reduzir aos conteúdos de Biologia. Mesmo quando há conteúdos próprios do arcabouço da Física, na maior parte dos casos, eles não são identificados ou reconhecidos como "de Ciências" e, quando o são, concentram-se num dos dois semestres do $9^{\circ}$ ano. De qualquer modo, essa presença localizada na fase terminal desse nível de escolarização não se mostrou suficiente para que se possa dizer que há, na escola de ensino fundamental, canais que alimentem visões nefastas dos físicos e da Física.

Se tal argumentação estiver correta, significa dizer que as percepções das dificuldades com os conteúdos de Física, como tal, parecem se apresentar a partir do primeiro ano do ensino médio, do que decorre um corolário que responsabiliza, exclusivamente, esse nível de escolarização, pelas aversões dos alunos aos conteúdos de Física, bem como suas consequências.

Antes de apressada generalização dessa elaboração, é preciso ressaltar dois aspectos importantes: primeiro, é necessário 
aprofundar estudos que possam confirmar e, principalmente, ampliar a prospecção aqui iniciada e, segundo, é essencial evitar, de forma leviana, atribuir o peso desse fracasso, que é institucional (PATTO, 1990), somente ao trabalho dos professores, desta ou daquela disciplina.

Temos inúmeros e enormes problemas na área de formação e qualificação de professores, particularmente em disciplinas como Física, Química e Matemática. É muito simplista, e falso, imaginar que as suas superações sejam fáceis, rápidas e monofocais, no entanto, não se pode desconhecer que há horizontes promissores razoavelmente bem definidos, bastando aventurarmo-nos nos primeiros passos e, como no poema de Machado, começarmos a construir, caminhando, esse novo caminho.

\title{
Considerations about the origins of the difficulties with Physic's contents, after testimonies of students from a Fortaleza's public school
}

\begin{abstract}
Recognizing the existence of negative perceptions of physicists, as professionals, and Physics, as a curricular component of basic education, this work tries to identify the origin's indications of these aversions, how they could have been installed and evolved and if they could interfere on the student's learning. To do so a 'case study' was made on a Ceará's public high school; the data here presented are referred to the interviews, semistructured, done with 12 students of the three grades. The analysis of information, done through the impregnated lecture, suggests that are associations, almost exclusives, of the Sciences subject, in Middle School, with Biology; that there are correlations between difficulties with Math and Physics; and that there are teachers who are capable of involving their students, which allows the conclusion that the positive experiences, if taken place, happen of teachers isolated actions, the students don't know and don't like Math, fact that interferes with learning Physics and that the aversions to the Physics contents don't seem to begin in Middle School.

Key-words: Teaching-learning process. High school. Physics teaching.
\end{abstract}

\section{Referências}

ANDRÉ, Marli Eliza Dalmazo Afonso de. Estudo de caso em pesquisa e avaliação educacional. 3. ed. Brasília, DF: Liber Livro, 2005. 68 p.

BEARDSLEE, David C.; O'DOWD, Donald D. The college-student image of the scientist. Science, v. 133, n. 3457, p. 997-1001, mar. 1961.

BODIÃO, Idevaldo da Silva. As necessárias articulações entre as instituições de ensino superior e as secretarias de educação, na formulação e efetivação de políticas de formação profissional. In: SALES, José Álbio Moreira de et al. Formação e práticas docentes. Fortaleza: EdUECE, 2007. p. 41-51. 
BOGDAN, Robert; BIKLEN, Sari. Investigação qualitativa em educação. Porto, Portugal: Porto Editora, 1994. 331 p.

CANIATO, Rodolpho. Com ciência na educação: ideário e prática de uma alternativa brasileira para o ensino da ciência. Campinas, SP: Papirus, 1987.

CHAMBERS, David Wade. Stereotypic images of the scientist: the drawa-scientist test. Science Education, Danvers, v. 67, n. 2, p. 255-265, 1983.

D'AGOSTIN, Aline, et al. Os estudantes do ensino médio e sua relação com a física. In: REUNIÃO ANUAL DA SBPC, 58., 2006, Florianópolis. Anais ... Florianópolis: SBPC, 2006. Disponível em < http://www.sbpcnet.org.br/livro/58ra/SENIOR/RESUMOS/resumo_3601.html > . Acesso em: 11 jun. 2008.

FIOLHAIS, Carlos; TRINDADE, Jorge. Física no computador: o computador como uma ferramenta no ensino e na aprendizagem das ciências físicas. Revista Brasileira de Ensino de Física., São Paulo, v. 25, n. 3, set. 2003. Disponível em: <http://www.scielo.br/scielo.php?pid=S0102$-47442003000300002 E$ script $=$ sci_arttext $>$. Acesso em: 18 nov. 2010.

GEYMONAT, Ludovico. Galileo Galilei. São Paulo: Nova Fronteira, 1997.

GÓMEZGIL, Maria Luisa Rodriguez Sala de. Mexican adolescent's image of the scientist. Social Studies of Science, London, v. 5, p. 355-361, 1975.

GRUPO DE REELABORAÇÃO DO ENSINO DE FÍSICA. Física 1: mecânica. São Paulo: EDUSP, 1990.

LIBÂNEO, José Carlos. Tendências pedagógicas na prática escolar. In: LUCKESI, Cipriano Carlos. Filosofia da educação. São Paulo: Cortez, 1993. p. 53-75.

LÜDKE, Menga; ANDRÉ, Marli Eliza Dalmazo Afonso de. Pesquisa em educação: abordardagens qualitativas. São Paulo: E.P.U, 1986.

MAURINA, Keli Cristina; PINHEIRO, Terezinha de Fátima. Física: expectativas criadas, obstáculos gerados? In: ENCONTRO NACIONAL DE PESQUISA EM EDUCAÇÃO EM CIÊNCIAS, 5., 2005, Bauru, SP. Atas ... Bauru, SP: Abrapec, 2005. Disponível em < http://www4.fc.unesp.br/ abrapec/venpec/atas/conteudo/paineltitulo.htm >. Acesso em: 10 abr. 2007.

MEAD, Margaret; MÉTRAUX, Rhoda. Image of scientist among high-school students: a pilot study. Science, v. 126, p. 384-390, ago. 1957.

MICHELAT, Guy. Sobre a utilização da entrevista não-diretiva em Sociologia. In: THIOLLENT, Michel. Crítica metodológica, investigação social e enquete operária. São Paulo: Pólis, 1982. p. 194-212.

MIZUKAMI, Maria da Graça Nicoletti. Ensino: as abordagens do processo. São Paulo: E.P.U., 1986. 
MOURA, Graziella Ribeiro Soares; VALE, José Misael Ferreira do. O ensino de Ciências na $5^{\text {a }}$ e na $6^{\text {a }}$ séries da Escola Fundamental. In: NARDI, Roberto (Org.). Educação em ciências: da pesquisa à prática docente. São Paulo: Escrituras, 2001. p. 135-143.

NÓVOA, António (Org.). Os professores e sua formação. Lisboa: Dom Quixote, 1997. 158 p.

PARRILLA, Angeles; DANIELS, Harry. Criação e desenvolvimento de grupo de apoio entre professores. São Paulo: Loyola, 2004. 207 p.

PATTO, Maria Helena Souza. A produção do fracasso escolar: histórias de submissão e rebeldia. São Paulo: T. A. Queiroz, 1990.

PIMENTA, Sema Garrido; GHEDIN, Evandro (Org.). Professor reflexivo: gênese e crítica de um conceito. São Paulo: Cortez, 2002.

PROJETO DE ENSINO DE FÍSICA. Mecânica. Rio de Janeiro: MEC/ FAE/PREMEN, 1984.

RAMALHO JUNIOR, Francisco; FERRARO, Nicolau Gilberto; SOARES, Paulo Antônio de Toledo. Os fundamentos da física. 9. ed. São Paulo: Moderna, 2007. 3 v.

ROSA, Cleci Terezinha da; ROSA, Álvaro Becker da. A teoria histórico-cultural e o ensino da Física. Revista Iberoamericana de Educación, n. 33/6, p. 1-8, 2004. Disponível em: < http://www.rieoei.org/ deloslectores/654Werner108.PDF > . Acesso em: 18 nov. 2010.

SCARINCI, Anne Louise. Tirando o coelho da cartola: a atuação do formador em um programa de desenvolvimento profissional docente. 2010. 220 f. Tese (Doutorado em Educação) - Faculdade de Educação, Universidade de São Paulo, São Paulo, 2010.

SILVA, Aparecida Valquíria Pereira da; SAAD, Fuad Daher. Problemas e perspectivas do ensino de física no município de Bauru, SP. In: NARDI, Roberto (Org.). Pesquisas em ensino de fisica. São Paulo: Escrituras, 2001. p. 47-56.

SZAJNBERG, Mordka; ZAKON, Abraham. A ampliação e a readequação do ensino da Física para a engenharia do terceiro milênio. In: ENCONTRO DE ENSINO DE ENGENHARIA, 7., 2001, Petrópolis. Anais ... Petrópolis, RJ, 2001. Disponível em: <http://www.dee.ufrj.br/VIIEEE/ VIIEncontro/defult.htm >. Acesso em: 11 jun. 2008.

Artigo submetido em 01/02/2012 e aceito para publicação em 17/05/2012. 